\title{
Diversidade na aula de Língua Portuguesa: um olhar discursivo ao que diz a BNCC
}

\author{
Mary Neiva Surdi da Luz \\ Jancileidi Hübner ${ }^{2}$ \\ Maria Cecília Halmenschlager Konzen ${ }^{3}$
}

Resumo: O presente trabalho analisa como a Base Nacional Comum Curricular discursiviza questões relacionadas à diversidade e ao trato com o diferente. O desenvolvimento do trabalho tomou como referência e corpus de análise uma sequência discursiva recortada das diretrizes que o documento apresenta para o componente curricular Língua Portuguesa. O olhar lançado ao recorte tomou como base a Análise de Discurso de vertente francesa e teve como objetivo principal refletir sobre os efeitos de sentido que o posicionamento do documento faz circular.

Palavras-chave: BNCC. Diversidade. Discurso de Ódio. Língua Portuguesa.

Abstract: This paper analyzes how Base Nacional Comum Curricular addresses questions related to the diversity and the treatment towards the different in its discourse. The development of the work took as reference and corpus for the analysis a discursive sequence cut out from the guidelines the document presents for the Portuguese Language curricular component. The view to the cut out is based on French Discourse Analysis and had as its main objective to ponder on sense effects that the stance of the document produces.

Key-words: BNCC. Diversity. Hate Speech. Portuguese Language

Resumen: El presente trabajo analiza cómo la Base Nacional Común Curricular produce discursos sobre cuestiones relacionadas a la diversidad y al modo que se trata el distinto. El desarrollo del trabajo ha tomado como referencia y corpus de análisis una secuencia discursiva sacada de las directrices que el documento presenta para el componente curricular Lengua Portuguesa. La mirada lanzada al recorte tomó como base el Análisis de Discurso de vertiente

\footnotetext{
${ }^{1}$ Doutora em Letras pela Universidade Federal de Santa Maria (2010). Atualmente é professor da Universidade Federal da Fronteira Sul, atuando nos Curso de Letras e Pedagogia e no Programa de Pós-Graduação Stricto Sensu em Estudos Linguísticos.

2 Professora de língua inglesa no Centro de Línguas da Universidade Regional Integrada do Alto Uruguai e das Missões e mestranda em Estudos Linguísticos na Universidade Federal da Fronteira Sul UFFS.

${ }^{3}$ Coordenadora do Programa PROEMI (Ensino Médio Inovador/Integral) desde 2014 na EEB Nossa Senhora da Salete. É mestranda no Programa de Pós-Graduação em Estudos Linguísticos da UFFS, de Chapecó / SC.
}

Este artigo está licenciado sob forma de uma licença Creative Commons Atribuição 4.0 Internacional, que permite uso irrestrito, distribuição e reprodução em qualquer meio, desde que a publicação

original seja corretamente citada. https://creativecommons.org/licenses/by/4.0/deed.pt BR. 
francesa y tuvo como objetivo principal reflexionar sobre los efectos de sentido que el posicionamiento del documento hace circular.

Palabras clave: BNCC. Diversidad. Discurso de Odio. Lengua Portuguesa.

\section{Introdução}

Este trabalho tem como principal objetivo lançar um olhar analítico à Base Nacional Comum Curricular (doravante BNCC) e à maneira pela qual esse documento se posiciona diante das polêmicas questões da diversidade e do trato com o diferente amplamente questionados em segmentos da sociedade contemporânea, principalmente em espaços de atuação juvenil como escolas e redes sociais.

A finalidade do presente texto é promover uma discussão sobre como o documento aborda o assunto e quais são as orientações trazidas para professores, principalmente os de Língua Portuguesa, e para a escola de maneira geral, a respeito da abertura de espaços que promovam habilidades relativas ao trato e ao respeito diante do diferente e à participação ética e crítica em discussões e debates de ideias em diversos âmbitos da sociedade contemporânea.

Partiremos do pressuposto de que dentre as funções da BNCC lhe é atribuída a função de ser um documento de referência cujo objetivo é embasar o currículo escolar nacional, seja ele de escola pública ou privada, definindo os conteúdos essenciais que todos os alunos devem desenvolver ao longo das etapas e das modalidades da Educação Básica. De acordo com o próprio documento, seu objetivo maior é fazer com que todos os alunos tenham a mesma oportunidade de aprender o que é fundamental para a construção de uma sociedade justa, democrática e inclusiva, como fundamentado nas Diretrizes Curriculares Nacionais da Educação Básica (DCN).

Para o estudo, tomaremos como referência um recorte do documento BNCC que será analisado sob as lentes teóricas da Análise de Discurso (doravante AD), de linha francesa, que entende o discurso como historicamente produzido e ideologicamente marcado. Para tal, partiremos do questionamento: que efeitos de sentido são produzidos

pela maneira pela qual a BNCC discursiviza a introdução, no currículo, do 
desenvolvimento de habilidades necessárias para o devido trato à diversidade e ao discurso de ódio?

Dessa forma, propomos uma reflexão no sentido de pensar discursivamente o espaço escolar como um espaço adequado para a construção de uma sociedade de respeito à dignidade humana, baseada em princípios éticos, de justiça, solidariedade, liberdade e autonomia. Um espaço onde se alavanque o compromisso com a promoção do bem estar de todos, contribuindo para combater e eliminar quaisquer manifestações de preconceito de origem, raça, sexo, cor, idade e quaisquer outras formas de discriminação, principalmente no contexto escolar.

Ao longo deste trabalho, portanto, a abordagem do documento será permeada por discussões concernentes à $\mathrm{AD}$ que se preocupam com a historicidade dos dizeres e com a maneira pela qual se produzem sentidos através do discurso. Nessa perspectiva, serão levantadas questões em torno da subjetividade e da identidade do sujeitoestudante ou do cidadão em geral enquanto sujeito de seu discurso e parte de uma sociedade contemporânea imersa em um espaço com fronteiras redefinidas pela expansão da cultura digital.

\section{Cultura digital e diversidade: breves reflexões sobre as diretrizes da BNCC para o componente curricular Língua Portuguesa.}

Julgando importante atentar às transformações das práticas de linguagem decorrentes deste século, ao abordar o componente curricular Língua Portuguesa, a BNCC assume uma perspectiva enunciativa-discursiva de linguagem e assevera a necessidade de o ensino acompanhar o desenvolvimento das tecnologias digitais da informação e comunicação (doravante TDICs) ao invés de tratar o estudante como sujeito alheio a esse processo.

Atrelado a tais pressupostos, o documento destaca a recolocação das fronteiras entre o público e o privado ocasionada pela popularidade da web, o excesso de exposição nas redes sociais, a viralização de conteúdos a respeito dos quais as opiniões importam 
mais que os fatos especificamente, entre outros fenômenos contemporâneos de crescente ocorrência na internet. Assim, rejeitando a ideia ultrapassada de lutar contra esses fenômenos, sugere que a melhor postura diante da nova realidade sociocultural seja a de refletir sobre essas redefinições de limites e impulsionar o desenvolvimento de habilidades para esse trato.

Em meio a essa nova realidade, a BNCC enfatiza ainda o fato de a internet possibilitar que todos os indivíduos postem e façam circular qualquer conteúdo sem ter critérios editoriais ou seleção adequada. O ambiente virtual caracteriza potencialmente, dessa maneira, o lugar onde a liberdade de expressão se concretiza e as divergências ou as diferenças circulam, pois todas as pessoas têm voz e são livres para expor suas opiniões. Além disso, é importante ressaltar que esse ambiente virtual é de muito fácil acesso e indivíduos de todas as idades podem entrar em contato com os discursos que aí circulam. Por isso, ao instigar a inclusão das práticas da cultura digital no currículo de Língua Portuguesa, a BNCC levanta o seguinte questionamento: "em tese, a Web é democrática: todos podem acessá-la e alimentá-la continuamente. Mas se esse espaço é livre e bastante familiar para crianças, adolescentes e jovens de hoje, por que a escola teria que, de alguma forma, considerá-lo?” (BNCC, 2016, p. 66).

A resposta a esse questionamento suscita reflexões em torno do papel da escola e do professor de Língua Portuguesa diante da realidade contemporânea impulsionada pelo desenvolvimento da cultura digital. De acordo com o documento, mesmo que os estudantes usem e estejam familiarizados com este novo ambiente de interação, não significa que estejam preparados para levar em conta as dimensões éticas e políticas desse uso. É necessário que se desenvolva a habilidade de lidar de forma crítica com os conteúdos que circulam na web.

Ressaltando, então, a questão da diversidade e do posicionamento crítico necessário diante do conteúdo digital, o documento destaca que "se, potencialmente, a internet seria o lugar para a divergência e o diferente circularem, na prática, a maioria das interações se dá em diferentes bolhas, em que o outro é parecido e pensa de forma semelhante" (BNCC, 2016, p. 66). Ou seja, passam a existir grupos que compartilham visões, posicionamentos, que se aceitam e convivem real ou virtualmente, mas que não enxergam o outro naquele mesmo ambiente e, dessa forma, não convivem de maneira adequada ou não aceitam o diferente. 
Essa forma desacertada de lidar com a diversidade faz com que o direito à liberdade de expressão abra espaço para a proliferação de discursos carregados de preconceito que ofendem as minorias. Essa é uma questão polêmica amplamente discutida pela BNCC e que merece grande atenção da escola e dos profissionais da educação.

Muito se tem estudado a respeito da tênue linha que divide o que pode ser categorizado como exercício da liberdade de expressão e o que se vale desse direito para produzir sentidos carregados de preconceito, discriminação e intolerância. Segundo o documento, é importante fazer com que o sujeito-estudante aprenda a "diferenciar liberdade de expressão de discursos de ódio, posicionando-se contrariamente a esse tipo de discurso e vislumbrando possibilidades de denúncia quando for o caso" (BNCC, 2016, p. 139).

Esse tipo de expressão que instiga opiniões divergentes pode ser entendido como "toda manifestação que denigra ou ofenda os membros das minorias tradicionalmente discriminadas, que estão em inferioridade numérica ou em situação de subordinação socioeconômica, política ou cultural" (LUNA e SANTOS, 2014, p. 232). Ou seja, são formas de expressão que promovem o ódio racial, a homofobia, a xenofobia, entre outras posturas preconceituosas e intolerantes.

Sabemos que a proteção da liberdade é característica fundamental de um ambiente democrático e inclusivo, que é o que a escola deveria caracterizar. No entanto, algumas questões permanecem sem contornos bem definidos em se tratando de liberdade de expressão. A exteriorização de conteúdos discriminatórios que acontece por meio do discurso de ódio, por exemplo, caracteriza um exercício abusivo da liberdade que dificilmente é tratado como deveria ser, por ter fronteiras imprecisas que dificultam estabelecer em que ponto o abuso da liberdade de expressão passa a existir.

Ao considerar a necessidade de abordar a proliferação desse tipo de discurso na contemporaneidade, a BNCC destaca que uma de suas principais premissas está pautada na diversidade cultural e que o ambiente escolar deve promover a interação e o devido 
trato com o diferente. Portanto, a seguir, analisaremos um recorte ${ }^{4}$ do documento oficial, tomado como uma sequência discursiva de referência (SDR), e teceremos reflexões em torno de questões de identidade e subjetividade inerentes ao convívio com o diferente.

\section{Reconhecimento e reflexão: habilidades necessárias diante da proliferação dos discursos de ódio.}

Ao abordar o componente curricular Língua Portuguesa, objetivando promover a participação crítica e significativa do estudante nas práticas sociais que se constituem pela linguagem, a BNCC sugere que as experiências em sala de aula devam contribuir para a ampliação dos letramentos de forma a englobar as novas práticas de linguagem contemporâneas.

Assim, ao elucidar a demanda da escola diante do cenário apresentado, o documento destaca algumas habilidades essenciais que devem ser desenvolvidas no sujeito-estudante. Segundo o documento,

SDR - É preciso saber reconhecer os discursos de ódio, refletir sobre os limites entre liberdade de expressão e ataque a direitos, aprender a debater ideias, considerando posições e argumentos contrários (BNCC, 2016, p. 67).

Tomando essa sequência discursiva como referência, observamos que, segundo o documento analisado, a questão da tênue linha entre a liberdade de expressão e seu exercício abusivo materializado em "discursos de ódio" e/ou “ataque a direitos" deve ser abordada na sala de aula de Língua Portuguesa com o intuito de tornar o sujeitoestudante capaz de "reconhecer" essas formas de expressão e "refletir" sobre seus limites.

Ao considerarmos essa complexa necessidade, buscamos outras fontes que

\footnotetext{
${ }^{4} \mathrm{O}$ recorte é o resultado da relação entre a pergunta básica do analista e o material da análise. $\mathrm{O}$ recorte é considerado como uma unidade discursiva, um fragmento indissociável da linguagem e da situação (ORLANDI, 1987, p. 139).
} 
abordam essa questão e destacamos o que nos dizem Luna e Santos (2014) ao fazer um estudo de cunho jurídico do discurso de ódio. Segundo os autores, no Brasil, o número de ações judiciais envolvendo esta temática é pequeno e isso não se deve à falta de discriminação, mas sim, ao fato de que este preconceito se manifesta de forma implícita, velada e até mesmo por meio do humor, dificultando seu combate.

Como vimos, definir os limites da liberdade de expressão não é algo simples e, portanto, são vários os aspectos a serem ponderados com esse intuito. Segundo Rothenburg e Stroppa (2015), essa tentativa de demarcar as fronteiras do discurso de ódio deve permear os seguintes aspectos:

a começar, obviamente, pela severidade da ofensa e pelo grau de generalidade das imputações, mas a levar em conta também o autor (por exemplo, se ele fala a partir de uma posição de destaque social, como um agente político, servidor público ou artista), o contexto (por exemplo, uma entrevista, uma palestra ou uma música), a situação da vítima (por exemplo, sua vulnerabilidade social ou se ela é afetada individualmente ou enquanto membro de determinado grupo), a forma de divulgação (por exemplo, uma charge, uma opinião ou uma notícia inseridas em um blog ou rede social) e a probabilidade de que o discurso possa, de fato, ensejar o ódio e suscitar algum nível de risco de que algum dano resulte de tal incitação (ROTHENBURG; STROPPA, 2015, p. 13).

Observando essa série de fatores listados por Rothenburg e Stroppa (2015), "reconhecer" e "refletir" sobre a discursivização do ódio e do preconceito exige uma proposta que vem ao encontro dos estudos discursivos. Conforme sugerem os autores, à medida que se toma o discurso de ódio como situado em um contexto sócio-histórico no qual importam os sujeitos envolvidos e as condições de produção, o fio do discurso deixa emergir a historicidade daquela materialidade linguística e os dizeres outros já proferidos anteriormente e que funcionam na atualização e produção de sentidos.

Nesse ínterim, seguindo o percurso teórico de viés discursivo que embasa as considerações aqui tecidas, destacamos o princípio de que quando falamos em discurso, estamos nos referindo à seguinte concepção: “discurso é efeito de sentidos entre interlocutores" (ORLANDI, 2001, p. 21), ou seja, é a língua em uso produzindo sentidos por e para sujeitos. Ressaltamos, também, que no momento em que o discurso é materializado através da língua, o indivíduo toma posições, mesmo que inconscientes, 
tornando-se sujeito do discurso e mostrando através dos já-ditos constitutivos de seu próprio dizer suas identificações.

Abordar o discurso de ódio em sala de aula, então, exige um olhar atento tanto do sujeito-professor, quanto dos sujeitos alunos, em direção à historicidade do dizer. O que importa para as reflexões das análises discursivas é como os discursos significam e, dessa forma, o ponto central das discussões é pautado na memória e nos já-ditos que estruturam os sentidos.

Assim, ao refletirmos sobre o discurso de ódio, buscamos respaldo em Pêcheux e Orlandi a fim de definir a concepção de memória a que nos referimos no presente texto. Segundo Pêcheux (2010, p. 50), a memória desloca-se da acepção cognitiva de lembrança e evoca a noção de memória discursiva, perceptível nos "entrecruzados da memória mítica, da memória social inscrita em práticas, e da memória construída do historiador".

O processo discursivo, dessa forma, se dá em dois planos: o do intradiscurso e o do interdiscurso. Conforme destaca Orlandi (2001, p. 33), "todo dizer, na realidade, se encontra na confluência dos dois eixos: o da memória (constituição) e o da atualidade (formulação)". Segundo ela, o intradiscurso é o eixo da formulação, exatamente o que se diz naquele momento, naquelas condições, e o interdiscurso é o eixo da constituição, o que determina a formulação, ou seja, a historicidade, a memória, "todo o conjunto de formulações feitas e já esquecidas que determinam o que dizemos" (ORLANDI, 2001, p. 33).

Ao discorrer sobre a proliferação do discurso de ódio por esse viés, consideramos que o discurso não é algo inédito, visto que já existe muito antes do indivíduo existir. Para Pêcheux (2014), a produção do discurso se dá a partir dos pré-construídos, a partir do interdiscurso, onde o indivíduo é interpelado em sujeito pela identificação com uma formação discursiva dominante e, embora o sujeito acredite ilusoriamente ser a fonte do seu discurso, ele é somente o suporte e o efeito do mesmo.

É importante ressaltar que o sujeito a que nos referimos é cindido, conforme os autores basilares deste estudo, e cujo discurso, no desejo de controlar os sentidos, exibe falhas, furos, transformando a linguagem num lugar de equívoco. Tomamos, dessa forma, o sujeito compreendido como ser assujeitado, como efeito de linguagem; constituído pela língua, atravessado pelo inconsciente, e, portanto, dividido e 
heterogêneo, sendo estruturado pela contradição, pela dispersão e pelo equívoco que denota a descontinuidade e a incompletude (ORLANDI, 2001; PÊCHEUX, 1997).

Conforme já mencionado anteriormente, durante o dizer, esse sujeito do discurso se identifica com uma formação discursiva dominante. Segundo Pêcheux (2014), pensar em formação discursiva é pensar em posições dadas em determinadas conjunturas estabelecidas pela luta de classes. É o que determina, segundo ele, "o que pode e deve ser dito" (PÊCHEUX, 2014, p. 147) em determinadas situações por determinados sujeitos. Ou seja, as tomadas de posição dos indivíduos que materializam o discurso de ódio na contemporaneidade são atravessadas e determinadas pela formação discursiva com que eles se identificam no momento em que são interpelados em sujeitos.

Esse movimento que constitui a subjetividade e produz sentidos dentro de uma determinada formação discursiva traz para essa discussão também a ideia de formação ideológica, pois sabemos que uma só existe através da outra. $\mathrm{O}$ funcionamento da ideologia nessas formações de cunho sócio-histórico é o que possibilita a significação, pois, segundo destaca Orlandi (2001), "[...] a ideologia torna possível a relação entre o pensamento, a linguagem e o mundo. Ou, em outras palavras, reúne sujeito e sentido. Desse modo o sujeito se constitui e o mundo significa. Pela ideologia" (ORLANDI, 20o1, p. 96).

Embasados nessas concepções, podemos ressaltar que a produção de sentidos que emerge do discurso de ódio, como de qualquer outro discurso, se dá por meio da ideologia. O sujeito, por sua vez, acredita ser a origem de seu dizer e não percebe a formação ideológica que o domina e o faz significar. É importante lembrarmos, portanto, como destaca Orlandi (1984), que "ao considerarmos o sujeito falante dentro da ordem social na qual ele vive, devemos reconhecer que ele não tem o domínio de sua fala [...] o dizer do sujeito é, por condição, constituído mesmo por aquilo que o sujeito não conhece mas está presente em seu discurso" (ORLANDI, 1984, p. 12-13).

A proliferação do ódio racial, da homofobia, da xenofobia, entre outras posturas preconceituosas e intolerantes por meio do discurso de ódio se filia a determinadas formações discursivas e ideológicas e, dessa forma, significa de maneiras diferenciadas e promove momentos de identificação dos sujeitos que caracterizam jogos de poder, constitutivos da luta de classes. 
Diante das questões apresentadas, destacamos que os efeitos de sentido produzidos pelo recorte "É preciso saber reconhecer os discursos de ódio, refletir sobre os limites entre liberdade de expressão e ataque a direitos" (BNCC, 2016, p. 67) nos levam a entender que saber qual posicionamento tomar em ambiente escolar e como desenvolver habilidades que possibilitem o devido trato diante da manifestação desses discursos é função de grande importância do sujeito-professor.

Essa questão, portanto, é abordada com posição de destaque na BNCC e foi trazida para discussão no presente trabalho a fim de salientar o vital papel do sujeitoprofessor ao guiar o sujeito-estudante pelo fio discursivo em busca de como os discursos

significam. É como se fosse necessário pegar o sujeito-estudante pela mão e, com ele, buscar pistas na historicidade do dizer com base na memória e nos já-ditos que constituem o sentido. Compreendemos, com base nas reflexões aqui tecidas, que esta seja uma maneira de ajudá-lo a identificar o que pode caracterizar um exercício abusivo da liberdade de expressão.

\section{Debater ideias e considerar posições diferentes: ações que devem ser estimuladas no ambiente escolar}

Voltamos, neste momento, para o recorte destacado anteriormente a fim de expor outra questão que merece atenção na forma pela qual a BNCC discursiviza as habilidades essenciais que devem ser desenvolvidas no sujeito-estudante. Tomamos, dessa forma, a sequência discursiva de referência neste trabalho e atentamos ao sentido de duas ações consideradas necessárias pelo documento: debater ideias e considerar posições diferentes.

Para tal, faz-se necessário ressaltar primeiramente que partimos do princípio de que ao engajar-se em um debate de ideias, o indivíduo toma posições a fim de defender seu ponto de vista, pois está filiado a uma formação discursiva dominante. Essa filiação de cunho ideológico não é estável e, dessa forma, é sujeita a transformações. Ou seja, uma formação discursiva é caracterizada pelas regularidades, constituída por ideias que se repetem, mas existe a possibilidade de deslocamento de sentidos. 
Aprender a debater ideias, uma habilidade essencial a ser desenvolvida no sujeito-estudante, conforme sugere a BNCC, é uma questão subjetiva que nos leva a repensar a "forma-sujeito do discurso" que se constitui nas formações discursivas, na qual, segundo Pêcheux (2014, p. 243), "coexistem, indissociavelmente, interpelação, identificação e produção de sentido". Desse modo, ressaltamos que os efeitos de sentido que emergem em um debate de ideias tem relação direta com as identificações do sujeito à medida que ele é interpelado ideologicamente.

Em Coracini (2000), podemos observar que os sujeitos se constituem por vozes que vão tecendo sua subjetividade a partir de identificações que vão estabilizando suas características e os transformam em sujeito em processo, ou em constante transformação. É o que acontece no desenho contemporâneo, por exemplo, no momento em que passam a existir grupos com as mesmas visões e posicionamentos que convivem real ou virtualmente e se aceitam na mesma proporção em que não estão abertos a aceitar o diferente de maneira adequada.

Instigar o debate de ideias é uma ação necessária no ambiente escolar para que se promova também a aceitação do diferente. Debater estando aberto a entender o posicionamento do outro e aceitar a diversidade é uma habilidade necessária no combate à proliferação de manifestações de preconceito como os discursos de ódio.

Por isso, conforme destacado no documento que embasa o currículo escolar brasileiro, é preciso promover a aprendizagem de debate de ideias "considerando posições e argumentos contrários" (BNCC, 2016, p. 67). Se tomarmos, nessa perspectiva, Eckert-Hoff (2015), sabemos que as identificações do sujeito estão em constante processo de construção, no qual ele se constitui, se relaciona e produz seu discurso a partir do outro, demarcando sua historicidade e heterogeneidade. Ou seja, no que concerne aos processos identitários, podemos afirmar que a identidade do sujeito se revela no e pelo discurso, à medida que ele se relaciona com o outro.

Isso significa, corroborando nossas reflexões anteriores, assumir que no momento da fala, da materialização do discurso através da língua, os indivíduos são interpelados em sujeitos e essa interpelação acontece, conforme destaca Orlandi (2006), através de um jogo de formações imaginárias: “a imagem que o sujeito faz dele mesmo, a imagem que ele faz de seu interlocutor, a imagem que ele faz do objeto do discurso" 
(ORLANDI, 2006, p. 15).

Portanto, a consideração de posições e argumentos contrários ao debater ideias, sugerida pela BNCC na sequência discursiva de referência, é uma ação complexa atravessada por filiações a formações discursivas, formações imaginárias e processos identitários heterogêneos constitutivos do sujeito na sua relação com o outro. Esta complexidade implica, sublinhemos isso, uma prática pedagógica aberta e atenta à diversidade cultural, que promova a interação e o trato adequado ao diferente.

\section{Considerações finais}

Para encaminharmos a presente reflexão a um fechamento, retomaremos brevemente questões que, no nosso entendimento, com base na leitura que realizamos da BNCC, são relevantes para que a aula de Língua Portuguesa promova um ambiente de crescimento do sujeito-estudante, desenvolvendo sua criticidade e o fazendo capaz de interagir de forma ética na sociedade contemporânea.

Primeiramente, destacamos a necessidade de a escola estar aberta a acompanhar o desenvolvimento das TDICs. A expansão da cultura digital trouxe à realidade do sujeito-estudante grandes transformações das práticas de linguagem e o papel da escola diante dessa nova realidade precisa ser refletido e reavaliado a fim de que a prática pedagógica desenvolva as habilidades essenciais necessárias para que o sujeitoestudante aja de maneira crítica, ética e aberta à diversidade em sua vida cotidiana.

A segunda questão a ser retomada e destacada consiste em promover habilidades que tornem o sujeito-estudante capaz de reconhecer manifestações preconceituosas como o discurso de ódio e refletir sobre as fronteiras entre a liberdade de expressão e o exercício abusivo desse direito. Consideramos, portanto, uma demanda da escola, e da aula de Língua Portuguesa principalmente, guiar o sujeito-estudante para que ele perceba o discurso de ódio como situado em um contexto sócio-histórico carregado de já-ditos que envolve a interação de sujeitos e no qual as condições de produção dos discursos também significam. Acreditamos que esta seja a única maneira de promover a 
habilidade de identificar os ataques a direitos com suas tênues fronteiras e perigosas consequências baseadas no exercício da liberdade de expressão.

Finalmente, como uma terceira questão relevante, é preciso ver o sujeitoestudante como sujeito do discurso, interpelado ideologicamente e tecendo sua subjetividade a partir de identificações que vão estabilizando suas características e o fazem tomar posições através da materialização do discurso na língua. Com essa visão, cabe à escola estimular ações de compreensão do diferente, que possibilitem ao sujeitoestudante debater ideias, considerando o posicionamento do outro à medida que compreende a diversidade como constitutiva da sociedade.

Assim, com base nas três questões aqui ressaltadas, retomando os efeitos de sentido produzidos pela maneira pela qual a BNCC discursiviza a introdução, no currículo, do desenvolvimento de habilidades necessárias para o devido trato à diversidade e ao discurso de ódio, vemos no ambiente escolar um lugar que deve funcionar como um propulsor do posicionamento crítico e ético do sujeito-estudante.

Diante do desenho social contemporâneo imerso na cultura digital, o papel da escola está centrado em tomar o sujeito-estudante como quem está na fronteira entre o que pode ou deve ser dito e o que não deve dizer e torná-lo capaz de conseguir olhar para além daquilo que o constitui a fim de compreender o diferente e entender que vivemos em um mundo plural no qual a diversidade é o que nos concebe como parte de uma sociedade.

\section{Referências}

BRASIL. Ministério da Educação. Secretaria da Educação Básica. Base Nacional Comum Curricular. Brasília, DF, 2016. (Disponível em: < http://basenacionalcomum.mec.gov.br>. Acesso em: 30 mai. 2018. (Versão de 472 páginas)

CORACINI, Maria José. Subjetividade e Identidade do professor de Português. Trabalhos em Linguística Aplicada, Campinas, n. 36, p. 147-158, jul./dez., 2000. 
ECKERT-HOFF, Beatriz Maria. O Discurso do Sujeito - Professor em Formação: (Des)Construindo Subjetividades. In. Cad. Cedes, Campinas, v. 35, n. 95, p. 91-106, jan. abr. 2015

LUNA, Nevita Maria Pessoa de Aquino Franca; SANTOS, Gustavo Ferreira. Liberdade de expressão e discurso do ódio no Brasil. Revista Direito e Liberdade, Natal, v. 16, n. 3, p. 227-255, set./dez. 2014. Quadrimestral.

ROTHENBURG, Walter C.; STROPPA, Tatiana. Liberdade de expressão e discurso do ódio: o conflito discursivo nas redes sociais. IN: Anais do 30 Congresso Internacional de Direito e Contemporaneidade: mídias e direitos da sociedade em rede. Santa Maria: UFSM, 2015. Disponível em: http://www.ufsm.br/congressodireito/anais. Acesso em: 02 jun. 2018.

ORLANDI, Eni P. Análise de discurso. IN: ORLANDI, Eni P. e LAGAZZI-RODRIGUES, Suzy. (orgs.) Discurso e textualidade. Campinas: Pontes Editora, 2006. . Análise de discurso: princípios e procedimentos. Campinas, SP: Pontes, 2001. . A linguagem e seu funcionamento: as formas do discurso. 2.ed. Campinas: Pontes, 1987. . Linguistas: questões e controversias. Uberaba: Finbe, 1984.

PÊCHEUX, Michel. Semântica e discurso. Uma crítica à afirmação do óbvio. 5a ed. Tradução de Eni P. Orlandi et al. Campinas, Unicamp, 2014.

. Papel da memória. In: ACHARD, Pierre. et al. (Org.). Papel da memória. 3. ed. Trad. e introdução de José Horta Nunes. Campinas, SP: Pontes Editores, 2010, p. 49-57. . Análise automática do discurso (AAD-69). In: GADET, Francoise; HAK, Tony. Por uma análise automática do discurso: uma introdução à obra de M. Pêcheux. Campinas: Ed. da Unicamp, 1997.

\section{Recebido em 04/09/2018.} Aprovado em 05/11/2018. 